thin films for energy conversion, catalysis, and related processes; from atoms to sheets: growth and tribology of thin films; functionalization and characterization of nanofilms; two-dimensional materials: graphene and beyond; and sensors and instruments based on nanofilms. The opening plenary speaker is Amaia Zurutuza of Graphenea S.A., Spain.

In addition to the technical program, the conference offers an industrial panel breakfast meeting on the present and future of surface engineering in Europe.

The abstract deadline is November 30. Online registration begins December 1. More information can be found on the conference website at www.ecnf2018.org.

\title{
2018 SIAM Conference on Mathematical Aspects of Materials Science to be
} held July 9-13 www.siam.org/meetings/ms18

The 2018 Society for Industrial and
Applied Mathematics (SIAM) Conference on Mathematical Aspects of Materials Science will be held July 9-13 in Portland, Ore., USA.

It is sponsored by the SIAM Activity Group on Mathematical Aspects of Materials Science. The organizing committee co-chairs are Robert P. Lipton of Louisiana State University, USA, and Govind Menon of Brown University, USA.
This conference focuses on interdisciplinary approaches that bridge mathematical and computational methods to the science and engineering of materials, including all electronic structure, atomistic simulation, microstructures, continuum descriptions, thermodynamics, kinetics, analytical methods, stochastic methods, and computational methods. The conference provides a forum to highlight significant advances as well as critical or promising challenges.

The submission deadline for minisymposium proposals is November 30 . The submission deadline for contributed lecture, poster, and mini-symposium presentation abstracts is January 18. The travel fund application deadline is January 19. Preregistration ends June 11. More information is available at www.siam.org/meetings/ms 18 .

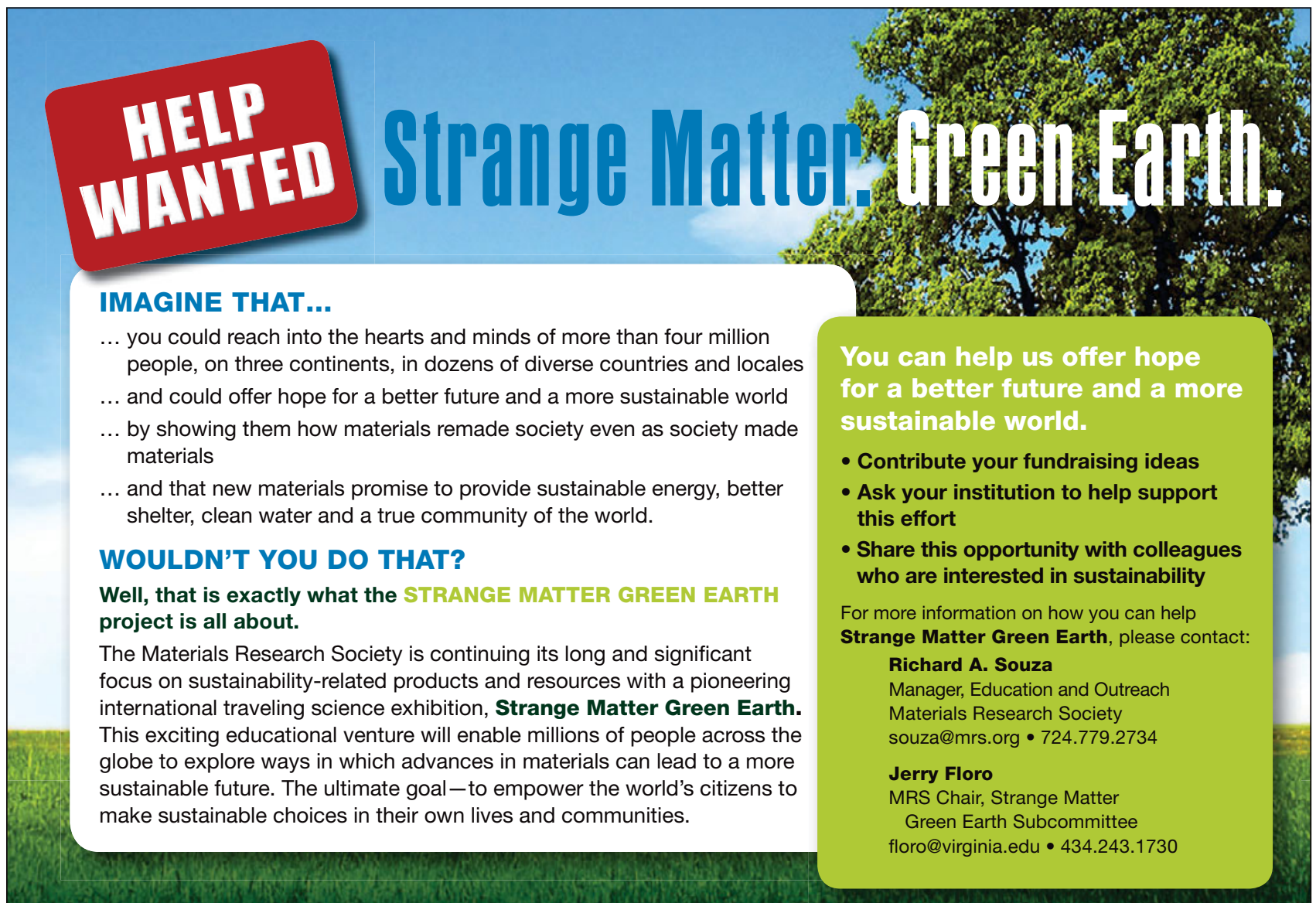

WWW.MRS.ORG/STRANGE-MATTER-GREEN-EARTH 